\title{
Sequential bipolar radiofrequency lumbar sympathectomy in Raynaud's disease
} -A case report-

\author{
Sang-Soo Kang, Keun-Man Shin, Sang-Moon Jung, Jun-Hee Park, and Seong-Jun Hong \\ Department of Anesthesiology and Pain Medicine, Kangdong Sacred Heart Hospital, Hallym University College of Medicine, Seoul, Korea
}

A 39-year-old female was suffering from cold-induced Raynaud's attacks in both hands and feet, with symptoms being most severe in her left foot. The patient did not respond to medical treatments and was referred to our department of pain medicine. We performed sequential bipolar radiofrequency lumbar sympathectomy to the patient, which offered a long duration of symptom relief. Sequential bipolar radiofrequency lesions could create continuous strip lesion, and thus, could achieve better results, while the potential risk of liquid neurolytic agents could be avoided. (Korean J Anesthesiol 2010; 59: 286-289)

Key Words: Bipolar, Lumbar sympathectomy, Radiofrequency, Raynaud's disease.

Raynaud's phenomenon induced by coldness and stress causes a peripheral vascular spasm accompanied by numbness, itchiness, and pain and moreover, skin ulcers in serious cases. Major treatment is the avoidance of the inducing factors and the administration of medication such as vasodilators. However, in case continuous pain or a skin ulcers occurs in spite of this medication, a sympathetic nerve block [1], chemical nerve destruction [2], or operative sympathectomy [3] are considered. The authors performed sequential bipolar radiofrequency (RF) thermocoagulation of lumbar sympathetic ganglion, which allowed a long duration of relief of symptoms of Raynaud's disease and hereby, we report the case and it's result.

\section{Case Report}

A 39-year-old woman (height: $158 \mathrm{~cm}$, body weight: $45 \mathrm{~kg}$ ) had taken nifedipine per oral from the department of the internal medicine for six months. For last one month the dose of nifedipine was increased due to uncontrolled spasmodic pain in her left toes while her face flushing and headache worsened and she was referred to the department of pain medicine. The blood test results showed nothing specific with the erythrocyte sedimentation rate (ESR) $3 \mathrm{~mm} / \mathrm{hr}$ and C-reactive protein (CRP) below $1 \mathrm{mg} / \mathrm{L}$. On physical examination, no lesions, such as skin ulcers or edema, on her hands and feet were found. After

Received: October 5, 2009. Revised: 1st, October 21, 2009; 2nd, October 30, 2009. Accepted: November 26, 2009.

Corresponding author: Keun-Man Shin, M.D., Department of Anesthesiology and Pain Medicine, Kangdong Sacred Heart Hospital, Hallym University College of Medicine, 445, Gil-dong, Gangdong-gu, Seoul 134-010, Korea. Tel: 82-2-2224-2209, Fax: 82-2-474-0956, E-mail: kmshin1@yahoo.co.kr (c) This is an open-access article distributed under the terms of the Creative Commons Attribution Non-Commercial License (http:// creativecommons.org/licenses/by-nc/3.0/), which permits unrestricted non-commercial use, distribution, and reproduction in any medium, provided the original work is properly cited. 
excluding the secondary causes such as connective tissue disease, arterial occlusive disease, artery disorder, patient was diagnosed with Raynaud's disease.

The authors performed a sympathetic nerve block using $0.2 \%$ ropivacaine $8.0 \mathrm{ml}$ at the level of upper third of the left L3 vertebral body and confirmed pain relief, but this symptom relief did not last for more than two days. The written consent was given for lumbar sympathectomy using bipolar RF thermocoagulation.

In the operation room, the dorsum of the patient was draped with betadine in a prone position on the radiographic surgery table. Non-invasive arterial blood pressure monitoring, an electrocardiogram, arterial oxygen saturation, and a skin temperature sensor (66S, Hewlett-Packard, USA) were attached to the insteps of both feet in order to observe the changes of temperature. After the local infiltration of $1 \%$ lidocaine $2.0 \mathrm{ml}$ on the skin by the lateral approach used for traditional lumbar sympathectomy, $10 \mathrm{~cm}$ RFK (Racz-Finch Kit, Radionics ${ }^{\circledR}$, USA) cannula with a curved $10 \mathrm{~mm}$ active tip was inserted at the level of the lower third of the left 2 vertebral body and the second cannula was inserted at approximately $7 \mathrm{~mm}$ below with the same method. We confirmed there was no spread to the psoas muscle by injecting $2.0 \mathrm{ml}$ of contrast material and checking the final location. A total of four cannulae were used in this procedure, and the procedure was sequentially performed from the lower third of the L2 vertebral body to the L2-3 intervertebral space with approximately $7 \mathrm{~mm}$ intervals (Fig. 1). After inserting an electrode into the needle, we confirmed there was no back pain at $50 \mathrm{~Hz}$ and 1 volt stimulation, and that there was no muscle contraction on the low back at $2 \mathrm{~Hz}$ and 3 volts stimulation. The first lesion was created at $80^{\circ} \mathrm{C}$ for 100 seconds spontaneously through each cannula. Next, the first cannula was removed and the third cannula was placed approximately $7 \mathrm{~mm}$ below the second cannula, and the second lesion was created with the same method. Subsequently, the second cannula was removed and the fourth cannula was inserted approximately $7 \mathrm{~mm}$ below the third cannula, and the third lesion was created the same way. The skin temperature of the left and right insteps, as measured before the operation, was $26.4^{\circ} \mathrm{C}$ and $26.6^{\circ} \mathrm{C}$, respectively. Five minutes after the creation of the lesions, the temperature of the left instep started to rise and the skin temperature of left and
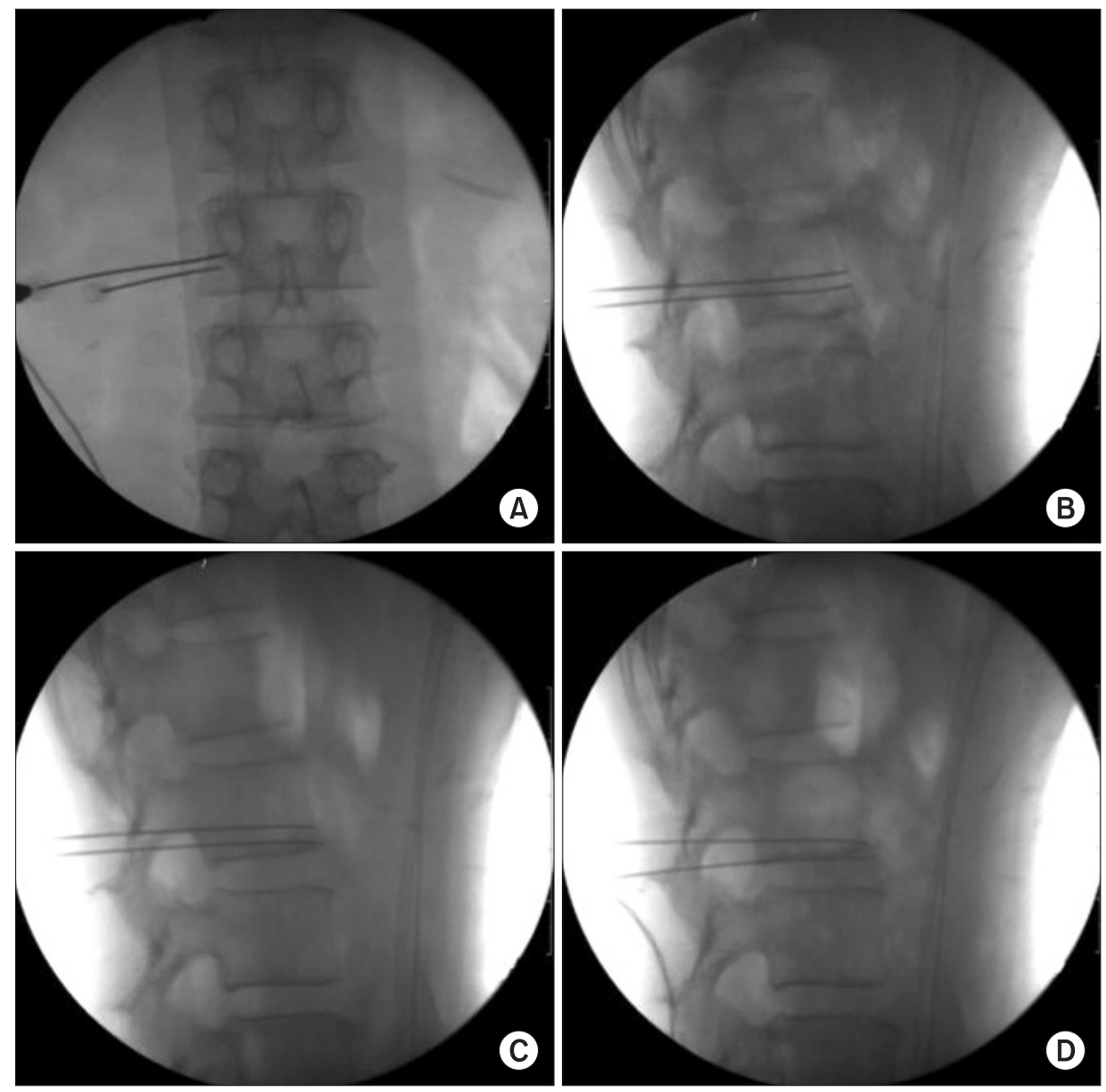

Fig. 1. This image shows the sequential bipolar radiofrequency (RF) lesions between the lower third of the L2 vertebral body and the L2-3 intervertebral space. (A) and (B) show the first and second needle in anteroposterior and lateral view; (C) shows the second and third needle; and (D) shows the third and fourth needle in lateral view. 


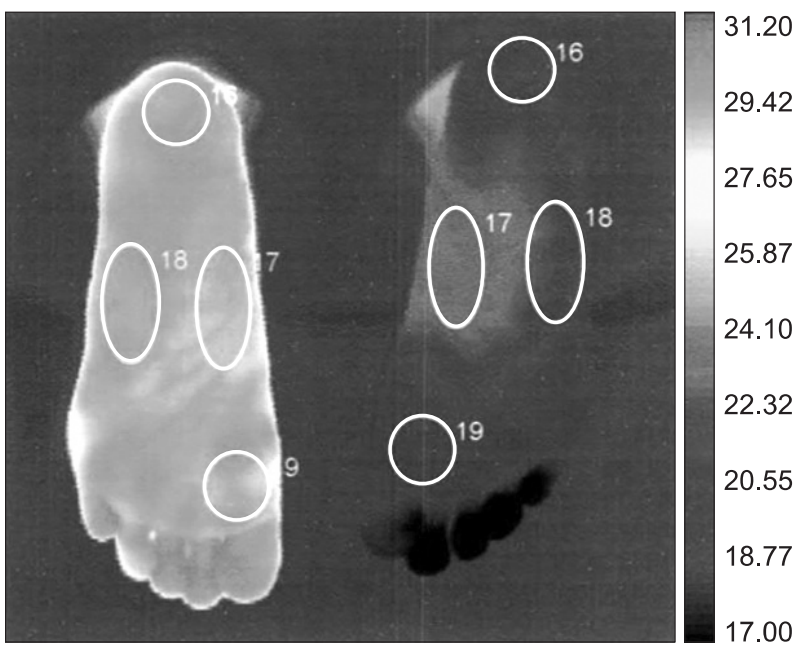

Region of interests

\begin{tabular}{|c|c|c|c|}
\hline NO & Rt & Lt & Difference \\
\hline 16 & 21.34 & 29.24 & -7.90 \\
\hline 17 & 23.44 & 28.76 & -5.32 \\
\hline 18 & 22.02 & 29.28 & -7.26 \\
\hline 19 & 20.35 & 28.92 & -8.57 \\
\hline
\end{tabular}

Fig. 2. This image shows the thermographic temperature difference between the right and left foot after the sequential bipolar RF lesions.

right insteps was measured as $26.8^{\circ} \mathrm{C}$ and $26.6^{\circ} \mathrm{C}$, respectively; the visual analog scale (VAS) decreased from $6-7$ before the operation to 0 after the operation. The skin temperature of the left and right insteps, as measured after 30 minutes, showed a definite difference, as it was $34.8^{\circ} \mathrm{C}$ and $28.6^{\circ} \mathrm{C}$, respectively. The average gap of the skin temperature of both feet was confirmed as $7.3^{\circ} \mathrm{C}$ when we performed infrared thermographic imaging (ITI) the next day (Fig. 2). No particular side effects or complications appeared after the operation, so the patient left the hospital two days later. The patient showed continuous improvement on the follow-ups performed two months later and one year later.

\section{Discussion}

Raynaud's phenomenon induced by an excessive contraction of the peripheral blood vessels in fingers, toes, ears, and nose, is due to exposure to low temperature or stress; the skin color of the influenced part turns white or blue accompanied by numbness, itchiness, and pain. More than $70 \%$ of the causes of this phenomenon are still obscure, and these are classified as primary Raynaud's phenomenon and separately called Raynaud's disease [4]. In addition, Raynaud's phenomenon may be accompanied by other diseases, referred as secondary Raynaud's phenomenon or Raynaud's syndrome [5]. The treat- ment for Raynaud's phenomenon is to decrease the frequency and the degree of spasm and to protect tissue from injury; for these purposes, lifestyle modifiaction and vasodilators are first line of therapy. Keeping warm temperatue especially hands and feet along with the house is the beginning of life style modification. Evading emotional stress, and ceasing cigarette are highly recommended. Any dose of beta-blockers, contraceptives, or migraine drugs with vasoconstricting effect should be avoided. Calcium channel blockers like nifedipine decrease the frequency and the degree of spasms in approximately two thirds of the patients and help to heal the skin ulcers of fingers and toes. However, in case the frequency and the degree of spasms worsen to the point of disturbing daily life, or in case continuous pain or a skin ulcer occurs in spite of the medication, a sympathetic nerve block [1], chemical nerve destruction [2], or operative sympathectomy [3] should be considered.

Traditionally, a lumbar sympathetic block is performed between the lower third of the L2 vertebral body and the upper third of the L3 vertebral body under C-arm guidance or computed tomography (CT); Umeda et al. [6], also reported that lumbar sympathetic ganglia is most frequently found at the level of the lower third of the second lumbar vertebra, at the L2-3 interspace, and at the level of the upper third of the third lumbar vertebra on both the right and left sides. Again in this case, the authors target the lumbar sympathetic ganglia between the lower third of the L2 vertebral body and the L2-3 intervertebral space. RF thermocoagulation, which has recently been applied in various pain treatments, is preferred to surgical removal or liquid neurolytic agent, since it makes selective nerve destruction easy by confirming the target nerve through the stimulation of sensory and motor nerves. Haynsworth and Noe [7] reported that percutaneous sympathectomy using RF thermocoagulation is expected to bring a long duration of pain relief and lower the incidence of post-operative neuralgia, as compared to chemical nerve destruction. Research document in Korean also reported that lumbar sympathectomy using RF thermocoagulation decreases the risk of complications in comparison with chemical nerve destruction using absolute alcohol, and it has effective treatment results in hyperhidrosis of lower limbs, sympathetically maintained pain (SMP), and vascular diseases [8].

Recently, many reports have focused on bipolar RF thermocoagulation that can create larger and more predictable lesions than monopolar RF thermocoagulation [9-11]. Derby and Lee [12] reported that in their experiment model where they placed two RF electrodes at $6 \mathrm{~mm}$ intervals and heated them simultaneously, the temperature of the core between the two electrodes exceeded $66^{\circ} \mathrm{C}$, so they might perform coagulation on a larger area, in case they used a bipolar electrode. Pino 
et al. [13], reported that the largest lesion in performing bipolar RF thermocoagulation was created at $90^{\circ} \mathrm{C}$ for $120-$ 150 seconds with $4-6 \mathrm{~mm}$ intervals of two electrodes. Korean researchers reported that a $5 \mathrm{~mm}$ active tip needed more than $80^{\circ} \mathrm{C}$ in temperature and 90 seconds in time within 6 $\mathrm{mm}$ intervals, and a $10 \mathrm{~mm}$ active tip $90^{\circ} \mathrm{C}$ and 120 seconds within $8 \mathrm{~mm}$ intervals, in order to create strip lesion, through bipolar RF thermocoagulation, using egg white as a medium [14]. In sacroiliac syndrome, it was reported that appropriate lesions were created over $90^{\circ} \mathrm{C}$ and more than 90 seconds of RF thermocoagulation within $1 \mathrm{~cm}$ intervals of the two electrodes [15]. In this case, the authors created lesions at $80^{\circ} \mathrm{C}$ for 100 seconds with approximately $7 \mathrm{~mm}$ intervals between $10 \mathrm{~mm}$ active tips based on the above documentation; in addition, we created three lesions sequentially, therefore, we expected that three sequential strip lesions would be created.

In conclusion, the authors suggest that creating sequential lesions using bipolar RF thermocoagulation is capable of making larger lesions than the existing monopolar RF thermocoagulation, and this leads to a higher rate of successful operations while simultaneously avoiding the side effects and complications from chemical nerve destruction. These findings mean that bipolar RF thermocoagulation may be effectively used for hyperhidrosis, SMP, and vascular diseases which need a long-term sympathetic nerve block.

\section{References}

1. Johansen KH. Pain due to vascular disease. In: Bonica's Management of Pain. 3rd ed. Edited by Loeser JD: Philadelphia, Lippincott Williams \& Wilkins. 2001, pp 604-6.

2. Skeehan TM, Cory PC Jr. Neurolytic lumbar sympathetic block in the treatment of Raynaud's phenomenon. Anesthesiology 1986; 64: 119-20.

3. Lowell RC, Gloviczki P, Cherry KJ Jr, Bower TC, Hallett JW Jr, Schirger A, et al. Cervicothoracic sympathectomy for Raynaud's syndrome.
Int Angiol 1993; 12: 168-72.

4. LeRoy EC, Medsger TA Jr. Raynaud's phenomenon: a proposal for classification. Clin Exp Rheumatol 1992; 10: 485-8.

5. Wigley FM. Clinical practice. Raynaud's Phenomenon. N Engl J Med 2002; 347: 1001-8.

6. Umeda S, Arai T, Hatano Y, Mori K, Hoshino K. Cadaver anatomic analysis of the best site for chemical lumbar sympathectomy. Anesth Analg 1987; 66: 643-6.

7. Haynsworth RF Jr, Noe CE. Percutaneous lumbar sympathectomy: a comparison of radiofrequency denervation versus phenol neurolysis. Anesthesiology 1991; 74: 459-63.

8. Chung YJ, Choi JB, Lee YW. Radiofrequency lumbar sympatholysis: comparison with neurolytic alcohol block. J Korean Pain Soc 2004; 17: 42-6.

9. Nakada SY, Jerde TJ, Warner TF, Wright AS, Haemmerich D, Mahvi DM, et al. Bipolar radiofrequency ablation of the kidney: comparison with monopolar radiofrequency ablation. J Endourol 2003; 17: 927-33.

10. Wang YG, Lu ZY, Zhao HY, Song YE, Li RL. A comparative study of radiofrequency ablation in unipolar and bipolar fashion. J Tongji Med Univ 1995; 15: 73-6.

11. Anfinsen OG, Kongsgaard E, Foerster A, Aass H, Amile JP. Radiofrequency current ablation of porcine right atrium: increased lesion size with bipolar two catheter technique compared to unipolar application in vitro and in vivo. Pacing Clin Electrophysiol 1998; 21: 69-78.

12. Derby R, Lee CH. The efficacy of a two needle electrode technique in percutaneous radiofrequency rhizotomy: an investigational laboratory study in an animal model. Pain Physician 2006; 9: 207 13.

13. Pino CA, Hoeft MA, Hofsess C, Rathmell JP. Morphologic analysis of bipolar radiofrequency lesions: implications for treatment of the sacroiliac joint. Reg Anesth Pain Med 2005; 30: 335-8.

14. Choi EM, Shin KM, Nam SK, Cheong IY. A study about size and shape of bipolar radiofrequency lesions. Korean J Anesthesiol 2008; 54: 197-200.

15. Ferrante FM, King LF, Roche EA, Kim PS, Aranda M, Delaney LR, et al. Radiofrequency sacroiliac joint denervation for sacroiliac syndrome. Reg Anesth Pain Med 2001; 26: 137-42. 